\title{
Perforated Retroperitoneal Appendicitis Presenting as Extensive Subcutaneous Emphysema of Abdominal and Chest Wall: An Unusual Presentation
}

\author{
Patel VK ${ }^{1}$, Gaharwar APS ${ }^{2}$, Batra RS ${ }^{3}$, Patel $\mathbf{U}^{4}$ \\ ${ }^{1}$ Dr. Vishnu Kumar Patel, Assistant Professor (Surgery), ${ }^{2}$ Dr. APS Gaharwar, Professor (Surgery), ${ }^{3}$ Dr. Rohan S Batra, Post \\ Graduate Student $3^{\text {rd }}$ year (Surgery) All are affiliated to S.S. Medical College, Rewa (MP), ${ }^{4}$ Dr. Umesh Patel, Associate \\ Professor (Pediatrics), L.N. Medical College, Bhopal (MP), India
}

Address for Corresponds: Dr. Vishnu Kumar Patel, Email: drvishnu.patel@gmail.com

\begin{abstract}
Acute appendicitis is a commonly encountered disease in surgical practice. Timely diagnosis and management prevents morbidity and mortality from this disease. Acute appendicitis may occasionally become extraordinarily complicated and life threatening yet difficult to diagnose. This atypical presentation is rare and required high index of suspicion. We present a case report of perforated retroperitoneal appendicitis, which presented to us with extensive subcutaneous emphysema of back and chest wall with no abdominal signs.
\end{abstract}

Keywords: Retroperitoneal Abscess, Acute Appendicitis, Subcutaneous Emphysema

\section{Introduction}

Acute appendicitis is a commonly encountered surgical emergency. Usually, the diagnosis is prompt due to typical abdominal signs and symptoms. Most of the time, the diagnosis and treatment of appendicitis are straightforward. However, atypical presentation can lead to missed diagnosis and life-threatening complications. When complicated by perforation, it typically presents with intra-peritoneal free air or abscess formation [1]. Many cases of acute appendicitis have been reported with perforation resulting in remote abscesses like retroperitoneal, gluteal region, groin or thigh and present diagnostic challenge [2-5]. In this rare case, the complicated acute appendicitis resulted into a perforation of cecum into the retroperitonium and formation of a retroperitoneal abscess which extended to the abdominal and chest wall as extensive subcutaneous emphysema and presented as respiratory distress without any peritoneal signs.

\section{Case Report}

A 40 years old non-diabetic and normotensive female patients presented in OPD with complains of high grade fever with chills and swelling over right side back, chest and face with difficulty in breathing for last 6 days.

Manuscript received: $14^{\text {st }}$ July 2014

Reviewed: $20^{\text {th }}$ July 2014

Author Corrected: $06^{\text {th }}$ Aug 2014

Accepted for Publication: $11^{\text {st }}$ Aug 2014
There was no history of abdominal discomfort or pain, bowel disturbance or trauma. She reported loss of appetite for last one week. On physical examination, she looked acutely ill with a pulse rate of $120 / \mathrm{min}$, respiratory rate of $36 / \mathrm{min}$, blood pressure of $110 / 60 \mathrm{mmHg}$, and febrile. Palpation of the abdomen did not reveal any focal or diffuse tenderness or organomegaly.

Rectal examination was unremarkable. On local examination subcutaneous emphysema was found on right side back, chest wall and face. Laboratory data indicated leukocytosis with WBC count of $11,400 / \mathrm{mm}^{3}$, mild anemia and all other blood chemistries were within normal range. Radiology of chest demonstrated extensive subcutaneous emphysema on right side chest wall extending to neck. Multiple incision \& drainage was done to relieve the respiratory distress.

Drain contains frank puss. The patient became afebrile and all the vitals settled down to normal. On the $3^{\text {rd }}$ day of incision, fecal matter was noted from the right lumbar wound and a suspicion of entero-cutaneous fistula was aroused. A CECT of abdomen and pelvis was performed, which revealed the abdominal wall collection connecting with cecum in the right iliac fossa and extending caudally to the extra peritoneal location of pelvis medial to the right internal oblique muscle with loculi of air in it. 
Pockets of free air was also seen into the peritoneal cavity. Exploratory laparotomy was done and no abdominal contamination was found. On mobilizing the cecum and the peritoneum, gangrenous appendix with tip lying towards the lumbar region posterior to the ascending colon with sloughing of appendix upto the base of appendix was seen, with perforation of the cecum. The appendicectomy was done with closure of the perforation in layers after freshening the perforation along with a proximal loop ileostomy. The post operative period of the patient was uneventful. After 12 weeks, the ileostomy was closed and patient recovered well.

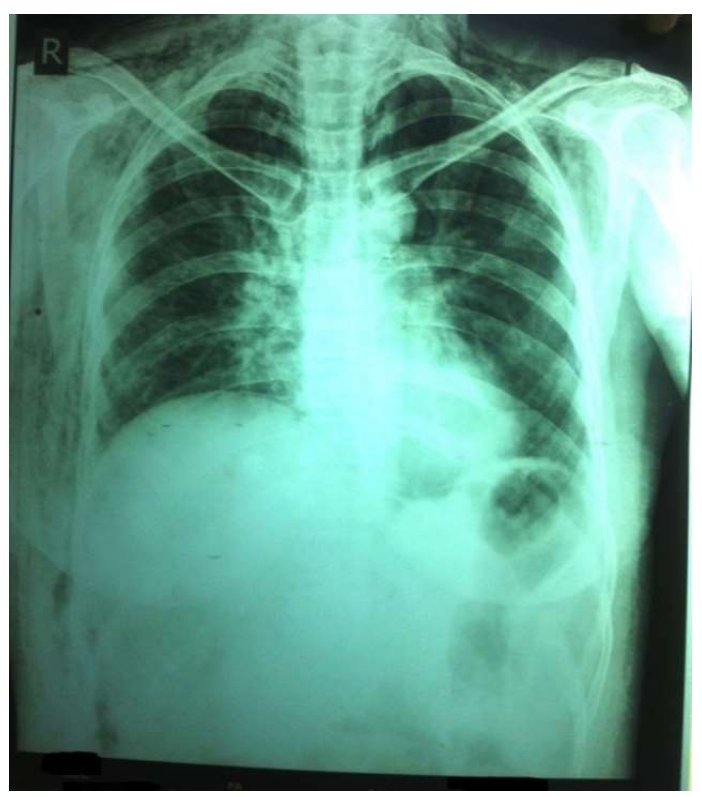

Fig 1: X Ray Chest showing right subcutaneous emphysema

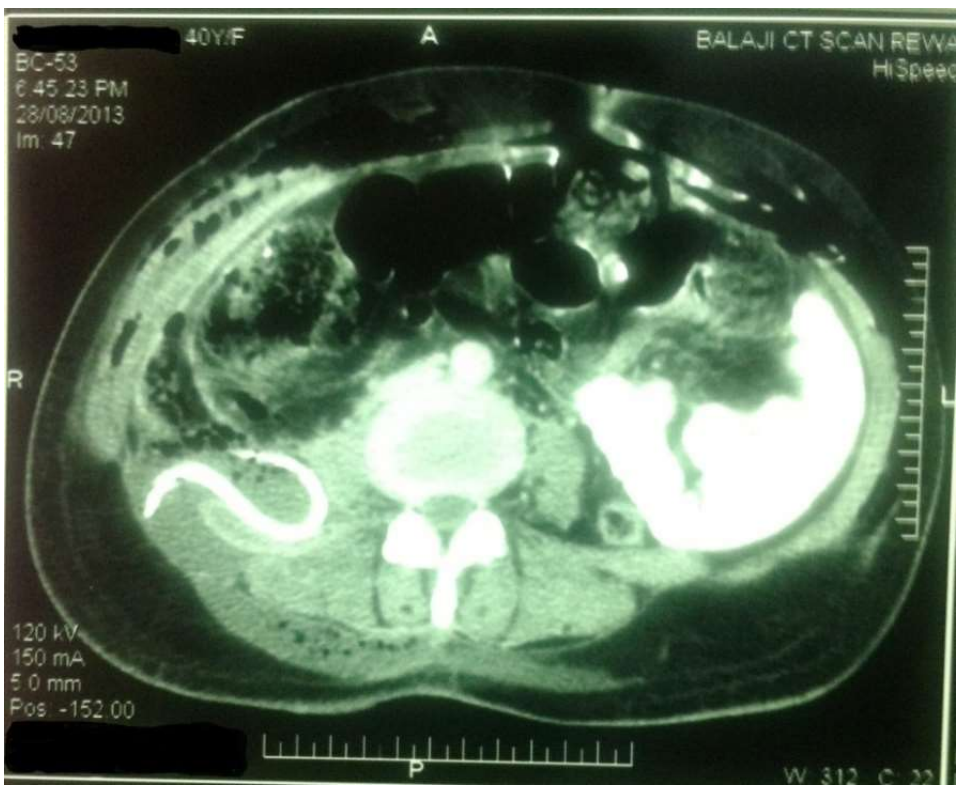

Fig 2: CECT showing thickening of right sided postero-lateral abdominal wall soft tissues with loculated collection in right paravertebral subcutaneous soft tissues

\section{Discussion}

Acute appendicitis is the most common abdominal emergency in worldwide. Lifetime risk of appendicitis is approximately 7\% [6]. Proper and timely diagnosis and treatment is essential to prevent morbidity and mortality. Patients usually presents with acute onset of vague abdominal pain that gradually shifts to right iliac fossa. 
These features make diagnosis straightforward, but in elder and pediatric patients, it may show a different pathogenesis, clinical course and outcome. Rarely atypical presentation can lead to misdiagnosis and patients can land up in life threatening condition. Retroperitoneal abscess because of acute appendicitis is relatively rare but serious surgical complication associated with significant morbidity and mortality. Review of literature surprise us that, there is lot of abdominal pathology like diverticulitis, perforated appendicitis, colorectal carcinoma, crohn's diseases, abdominal trauma and rarely suppurative iliac lymphadenitis, pyelonephritis and abdominal tuberculosis are causing retroperitoneal abscess formation with extension to abdominal wall, thigh, groin, psoas muscle and perinephric space, but acute appendicitis has rarely been discussed with extensive subcutaneous emphysema of abdominal and chest wall [4-7]. The complicated acute appendicitis represents here a retroperitoneal abscess which has extravasated in the subcutaneous space of the abdominal wall and the chest wall through medial side of the internal oblique muscle. Because of its position, a retroperitoneal perforated appendicitis can cause atypical and confusing physical findings and infection and air can extend to communicating compartments, resulting in emphysema and abscesses in unexpected anatomical sites. Since the location of infection in our patient was retroperitoneal, typical peritoneal signs were absent. The appendix in a retrocecal position is frequently retroperitoneal in location [8]. Various routes are present through which the intra-abdominal infection reaches the various sites [9$11]$.

Table 1: Route of spread of intra abdominal infection to extra abdominal sites

\begin{tabular}{|l|l|l|}
\hline S. No & \multicolumn{1}{|c|}{ Route } & \multicolumn{1}{c|}{ Tissue plane } \\
\hline 01 & Deep to inguinal ligament & Psoas sheath, Femoral sheath, Femoral canal \\
\hline 02 & Fibro-osseous canals & Sacrosciatic notch, Obturator foramen \\
\hline 03 & Abdominal wall & Subcutaneous (through lumbar triangles) \\
\hline 04 & Direct & Penetration of pelvic floor \\
\hline 05 & Generalized cellulitis & Septicemia/soft tissue planes \\
\hline
\end{tabular}

In many cases, like our case, history and presenting symptoms did not clearly indicate an intra-abdominal origin, and this has often created serious diagnostic problems. Currently, there is no test or objective physical finding which can rule out the presence of appendicitis with acceptable accuracy. Delayed presentation is the most common cause of morbidity and mortality. Early presentation and diagnosis, use of appropriate antibiotics and surgical intervention are important steps to reduced the morbidity. We are reporting it due to its rarity.

CT scan of abdomen and pelvis is the imaging modality which accurately defines the anatomical location of the abscess and the concurrent intra-abdominal pathology [12-14]. It can guide the clinician to an accurate diagnosis and extension of the involvement of the retroperitoneum and the subcutaneous tissue. Timely surgical intervention by exploratory laparotomy and drainage of the abscess by single or multiple incisions can prevent morbidity and mortality. Nonetheless, in our case, CT findings were not sufficient for the diagnosis and the cause of abscess and emphysema formation was unclear until laparotomy.

Abdominal ultrasonography is also a modality widely used for diagnosis of appendicitis and other abdominal pathologies.

\section{Conclusion}

A search for the presence of intra-abdominal pathology by a thorough clinical and radiological evaluation should be made in all patients with unexplained groin, thigh and abdominal swelling with fever and leukocytosis. Physician and surgeons should be aware that an abscess may be the manifestation of an intestinal disorder despite minimal abdominal signs and symptoms.

A CT scan accurately delineated the intra abdominal anatomy and pathological organ and guide the appropriate treatment. However, sometimes an exploratory laparotomy is necessary to reveal the cause.

\section{References}

1. Kawashima M , Hashimoto Y, Sudo T, Uemura K, Nakashima A, Sueda T, Murakami Y. A rare diagnostic challenge in acute appendicitis: a case report. Hiroshima J Med Sci. 2012 Mar;61(1):19-21.

2. Wani NA, Farooq M, Gojwari T, Kosar T. Perinephric abscess caused by retrocecal appendix: MDCT demonstration. Urol Ann. 2010 Jan-Aprl;2(10):29-31. 
3. El-Masry NS, Theodorou NA. Retroperitoneal perforation of the appendix presenting as right thigh abscess. Int Surg. 2002 April-Jun;87(2):61-4.

4. Hsieh CH, Wang YC, Yang HR, Chung PK, Jeng LB, Chen RJ. Extensive retroperitoneal and right thigh abscess in a patient with ruptured retrocecal appendicitis: an extremely fulminant form of a common disease. World J Gastroenterol. 2006 Jan;12(3):496-9.

5. Tomasoa NB, Ultee JM, Vrouenraets BC. Retroperitoneal abscess and extensive subcutaneous emphysema in perforated appendicitis: A case report. Acta Chir Belg. 2008 Jul-Aug;108(4):457-9.

6. Gurleyik G, Gurleyik E. Age-related clinical features in older patients with acute appendicitis. Eur J Emerg Med. 2003 Sep;10(3):200-3.

7. Yildiz M, Karakayali AS, Ozer S, Ozer H, Demir A, Kaptanoglu B. Acute appendicitis presenting with abdominal wall and right groin abscess: a case report. World J Gastroenterol. 2007 Jul 14;13(26):3631-3.

8. Saddique M, Iqbal P, Rajput A, Kumar R. Atypical presentation of appendicitis: diagnosis and management. J Surg Pak. 2009 Oct-Dec; 14 (4):157-60.
9. Lal S, Gupta, Gaharwar APS, Shrivastava GP. Thigh abscess is an unusual presentation of the perforation of retroperitoneal appendicitis. Journal of Clinical and Diagnostic Research [serial online] 2012 May; 6:457-9.

10. Ishigami K. Khanna G. Samuel I. Dahmoush L. Sato Y. Gasforming abdominal wall abscess : an unusual manifestation of a perforated retroperitoneal appendicitis which extended through the superior lumbar triangle. Emerg Radiol, 2004, 10: 207-29.

11. El-Masry NS1, Theodorou NA.Retroperitoneal perforation of the appendix presenting as right thigh abscess: Int Surg. 2002 Apr-Jun;87(2):61-4.

12. Edwards JD, Eckhauser FE. Retroperitoneal perforation of the appendix presenting as subcutaneous emphysema of the thigh. Dis Colon Rectum, 1986, 29, 456-458.

13. Gutknecht DR. Retroperitoneal abscess presenting as emphysema of the thigh. J Clin Gastro-enterol, 1997, 25 : 685-687.

14. Sharma SB,Gupta V, Sharma SC. Acute appendicitis presentingas thigh abscess in a child: a case report. Pediatr Surg Int, 2005, 21 : 298-300.

\section{How to cite this article?}

Patel VK, Gaharwar APS, Batra RS, Patel U. Perforated Retroperitoneal Appendicitis Presenting as Extensive Subcutaneous Emphysema of Abdominal and Chest Wall: An Unusual Presentation. Int J Med Res Rev 2014;2(5):511- 514. doi:10.17511/ijmrr.2014.i05.18 